\title{
Modification to Neurology Residency Training
}

\section{The Toronto Neurology COVID-19 Pandemic Experience}

\author{
Ryan T. Muir, MD, BHSc, Priti Gros, MD, Robert Ure, MD, BSc, Sara B. Mitchell, MD, MPH, \\ Charles D. Kassardjian, MD, MSc, Aaron Izenberg, MD, MSc, Peter Tai, MD, MSc, Houman Khosravani, MD, \\ PhD*, and David K. Chan, MD, MEd*
}

\author{
Correspondence \\ Dr. Chan \\ david.chan@unityhealth.to
}

Neurology: Clinical Practice April 2021 vol. 11 no. 2 e165-e169 doi:10.1212/CPJ.0000000000000894

\section{Abstract}

We describe the University of Toronto Adult Neurology Residency Program's early experiences with and response to the coronavirus disease 2019 pandemic, including modifications to the provision of neurologic care while upholding neurology education and safety. All academic and many patient-related activities were virtualized. This maintained physical distancing while creating a city-wide videoconference-based teaching curriculum, expanding the learning opportunities to trainees at all academic sites. Furthermore, we propose a novel split-team model to promote resident safety through physical distancing of teams and to establish a capacity to rapidly adapt to redeployment, service needs, and trainee illness. Finally, we developed a unique protected code stroke framework to safeguard staff and trainees during hyperacute stroke assessments in this pandemic. Our shared experiences highlight considerations for contingency planning, main-

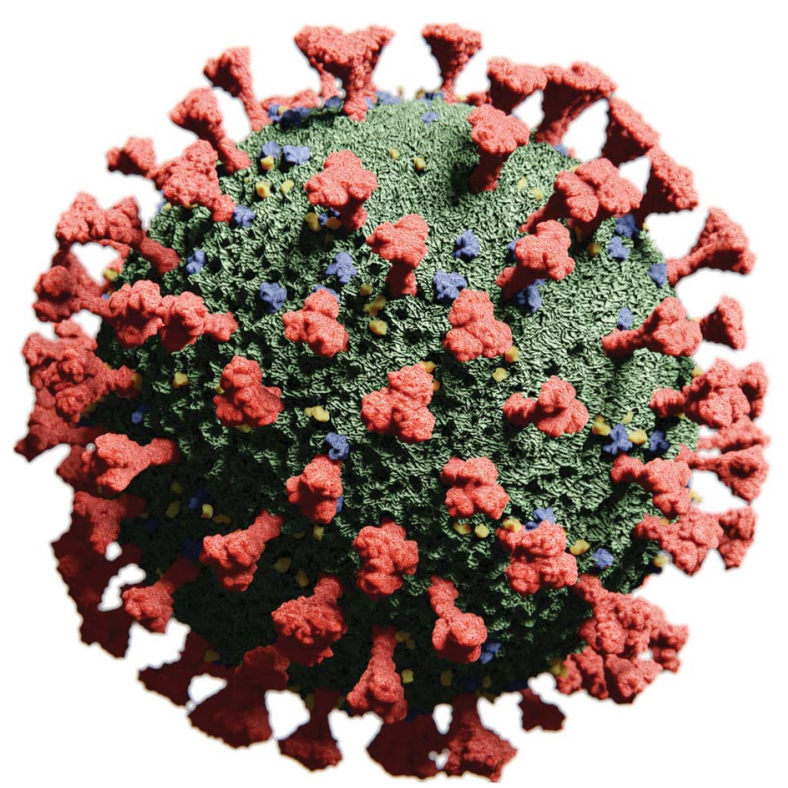
tenance of education, sustainability of team members, and promotion of safe neurologic care. These interventions serve to promote trainee safety, wellness, and resiliency.

The coronavirus disease 2019 (COVID-19) pandemic has affected more than 185 countries, surpassing 4.2 million cases and 290,000 deaths as of May 12, 2020. ${ }^{1,2}$ The clinical spectrum and disease severity related to COVID-19 is broad, but its inundating effect on health systems is universal.

Neurologists and neurology trainees will undoubtedly care for patients with neurologic manifestations of COVID-19 $9^{3-8}$ and also guide decisions regarding immunotherapy for patients with underlying neurologic diseases who contract COVID-19. ${ }^{9-11}$ Neurology trainees have been additionally affected in their education and well-being. Training experiences have been disrupted by alterations in rotations, electives, examinations, and redeployment to other services.
MORE ONLINE

COVID-19 Resources

For the latest articles, invited commentaries, and blogs from physicians around the world NPub.org/COVID19

Herein, we describe the University of Toronto Adult Neurology Residency Program's safety modifications to the provision of neurologic care while sustaining neurology education during the pandemic. Our program is the largest neurology training program in Canada and one of the largest in North America, with residents rotating through 1 of 7 academic and 4 community hospitals.

\footnotetext{
*These authors contributed equally to this work.
}

Adult Neurology Residency Program (RTM, PG, RU), Division of Neurology, Department of Medicine, University of Toronto; Division of Neurology (SBM, HK), Department of Medicine, Sunnybrook Health Sciences Centre \& University of Toronto; Division of Neurology (CDK, DKC), Department of Medicine, St. Michael's Hospital \& University of Toronto; Department of Psychiatry (SBM, Al), Sunnybrook Health Sciences Centre \& University of Toronto; Division of Neurology (PT), Department of Medicine, University Health Network \& University of Toronto; Division of Palliative Medicine (HK), Department of Medicine, University of Toronto; and Neurology Quality and Innovation Lab (SBM, CDK, HK), Toronto, ON, Canada. 


\section{Maintaining Safety: Modifications to Neurology Inpatient and Outpatient Care}

One of the lessons from the severe acute respiratory syndrome-associated coronavirus (SARS-CoV) and Middle East respiratory syndrome coronavirus outbreaks of 2003 and 2012, respectively, was the prevalence of nosocomial transmission. ${ }^{12}$ Nosocomial transmission is an emerging concern with COVID-19, prompting us to reorganize neurology services across our city to minimize nosocomial transmission risk and promote physical distancing.

Before March 2020, neurology residents would rotate among all academic hospitals in Toronto to maximize subspecialty exposure offered at each site. As an early safety intervention, we site restricted residents to prevent movement between hospitals. In addition, general neurology and stroke teams at each hospital were split into 2 or 3 teams (A, B, and C team model illustrated in table 1; A and B team model in table 2). Split-team models (1) promote physical distancing of health care professionals (HCPs), (2) reduce exposure risk by limiting the number of HCPs in the hospital any given day, and (3) provide a backup system and promote resilience should team members become ill, an entire team quarantined, or neurology residents redeployed to other services. This backup system did not exist before the pandemic and is partly facilitated by redeploying residents on nonclinical and ambulatory rotations to the inpatient neurology services. Recognizing the stresses involved in working in a hospital during a pandemic, backup residents provide important

Table 1 Restructured ABC Split-team Model of Neurology Care During the COVID-19 Pandemic

\begin{tabular}{|c|c|}
\hline Week 1 & Team A \\
\hline Week 1 backup & Team C \\
\hline Week 2 & Team B \\
\hline Week 2 backup & Team C \\
\hline Week 3 & Team A \\
\hline Week 3 backup & Team B \\
\hline Week 4 & Team C \\
\hline Week 4 backup & Team B \\
\hline \multicolumn{2}{|c|}{$\begin{array}{l}\text { Abbreviation: COVID-19 = coronavirus disease } 2019 \text {. } \\
\text { Residents at a particular site on neurology and/or stroke services are split } \\
\text { into } 1 \text { of } 3 \text { teams: A, B, or C each comprising } 2-3 \text { residents per team. In this } \\
\text { system, team A covers daytime service and overnight call during the first } \\
\text { week, and a different team C member serves as a } 24 \text {-hour backup, available } \\
\text { to join the team should the daytime team need assistance due to high } \\
\text { patient volumes or to cover overnight on-call service should a team A } \\
\text { member become ill. To help decrease the burden of call to team A members } \\
\text { during a week on active day service, members of the backup team are also } \\
\text { assigned to do overnight call to provide relief to team A. Although team A is } \\
\text { assigned to active day service for } 2 \text { of the } 4 \text { weeks, they do not serve as } \\
\text { backup during weeks that teams B and C serve as the primary active day } \\
\text { service. }\end{array}$} \\
\hline
\end{tabular}

Table 2 Restructured AB Split-team Model of Neurology Care During the COVID-19 Pandemic

\begin{tabular}{lc}
\hline Week 1 & Team A \\
\hline Week 1 backup & Team B \\
\hline Week 2 & Team B \\
\hline Week $\mathbf{2}$ backup & Team A \\
\hline Week $\mathbf{3}$ & Team A \\
\hline Week $\mathbf{3}$ backup & Team B \\
\hline Week 4 & Team B \\
\hline Week 4 backup & Team A \\
\hline
\end{tabular}

Abbreviation: COVID-19 = coronavirus disease 2019.

Residents at a particular site on neurology and/or stroke services are split into 1 of 2 teams: A or B comprises 3-4 residents per team. In this system, team A covers daytime service and overnight call during the first week, whereas team $B$ serves as a 24-hour backup, available to join the team should the daytime team need.

support for residents facing physical and emotional fatigue. We recognize that programs will vary in trainee numbers, and this system may not be universally feasible.

Between March and April 2020, we noted a drastic reduction in neurology inpatient volumes. At that time, most of our neurology services adopted the $\mathrm{ABC}$ model to prioritize physical distancing and safety; however, this model resulted in frequent handover between teams weekly. Increased consultation and admission volumes in late April and into May 2020 made small teams insufficient, and in response, all sites adopted the $\mathrm{AB}$ model. Although the $\mathrm{AB}$ model increased the size of teams, it reduced the amount of handover and better accommodated increasing patient volumes.

To further promote physical distancing of HCPs, all patientrelated rounds and handover have become virtual. We have also tried to limit the number of learners in contact with patients. Although new consultations are reviewed virtually with the attending physician and entire team to maintain learning around the cases, not all team members will observe the examination of the patient. Furthermore, before the pandemic, senior neurology residents were entrusted to triage initial consults and conduct initial patient assessments; currently, senior residents involve staff early in the consultation process to facilitate quick resolution of straightforward questions, reducing the movement of residents between wards. The latter became important during outbreaks within one of our hospitals. In this spirit, our residents also conducted more patient interviews by phone, and in cases where telephone consultation was sufficient, these were dictated rather than written into the patient's chart.

We also responded to several unexpected situations regarding our trainees. Specialty certification examinations were postponed for our fifth-year residents, which created uncertainty 
and disappointment. As these residents represent the most advanced trainees in our program, they were incorporated into the split-team model as junior attendings so that they continue to develop their skills as independent consultants.

COVID-19 has also significantly affected outpatient neurology care, as most ambulatory clinics have been suspended for in-person visits. Many have transitioned to virtual clinics. Residents on the backup team have been gaining valuable experience by participating in these virtual clinics, including weekly longitudinal/continuity neurology clinics. Virtual clinics pose several challenges with technical difficulties and a limited neurologic examination. With respect to the supervision of virtual consultations, residents complete the initial assessment, review the case with the staff neurologist, and then discuss the management plan with the patient via 3way videoconferencing.

\section{Modifications to Acute Stroke Care}

With 3 academic stroke centers in Toronto, we cumulatively assess 3,000 hyperacute cases annually. The often undifferentiated nature of hyperacute stroke consults and patients with a positive infectious screen and neurologic symptoms mimicking stroke motivated us to develop the concept of protected code stroke (PCS). ${ }^{13}$ All of our academic hospitals have rapidly adopted the PCS protocol with minor adjustments for local infection control practices (figure). Physical distancing and Crisis Resource Management is built into the PCS by limiting patient contact. A single physician, either a staff neurologist or senior neurology trainee, examines the patient and obtains the history along with the bedside emergency nurse, while a second physician is outside the room documenting the information. A third team member is designated as the Safety Lead to monitor personal protective equipment (PPE) use and to safeguard an open passage to imaging and/or the neuroangiography suite while ensuring that the environment is not contaminated. ${ }^{13}$

Programs with distributed stroke care across several academic hospitals served by trainees have the added challenge of adhering to local institutional practice patterns and policies. Inconsistency of interhospital and interdepartmental interpretation of public health directives and the lack of communication between institutions during previous outbreaks have been described. ${ }^{14}$ In light of this, we encouraged close integration of care models across sites to provide consistency for trainees when engaged in hyperacute stroke assessments during the pandemic. This was achieved through utilization of academic half-day lectures and ongoing weekly residency program virtual town hall meetings. Participants of these town hall meetings include all residents, the program director, education site directors, and the neurology residency program committee.

Figure Protected Code Stroke Pathway

Screening (if applicable, can consider ALL codes as protected)

- Prenotification

- Infection control screen

- Fever, cough, chest pain, dyspnea, headache, myalgias, emesis/GI symptoms

- Contact with an infected individual

- History of travel

- If $\underline{\text { ANY }}$ are POSITIVE? $\rightarrow$ proceed as a PCS

- Clinical features

- Lack of infectious control screen or unclear/unable to provide history

- Clinical and examination features suggestive of an alternate diagnosis

- If ANY are POSITIVE? $\rightarrow$ proceed as a PCS

$\underline{\text { Actions }} \rightarrow \underline{\text { Protected }}$ Code Stroke

- (1) Use droplet/contact PPE: Full-sleeved gown, surgical mask, face shield and/or goggles, and extended-cuff gloves

- Avoid aerosol-generating medical procedures (AGMPs):

- Avoid $\rightarrow$ Suctioning of secretions, NG tube insertion/induced coughing/sputum, intubation, BVM with manual ventilations, and noninvasive ventilation (BiPAP)

- $\quad$ AGMPs? $\rightarrow$ Use N95 mask in addition to above precautions. Consider neck protection

- (2) Place a mask on the nonintubated patient

- Supplemental nasal prongs $\mathrm{O} 2$ can be applied underneath mask (up to $6 \mathrm{~L} / \mathrm{min}$ max)

- If higher FiO2 requirements, use HiOx -or- Tavish mask, with exhalation filter

- At risk of deterioration or obtunded patient? $\rightarrow$ Consult appropriate ED/ICU MD, consider early airway management, as applicable, prior to transport to imaging

- (3) Use crisis resource management - "SAFE"

- Safety leader - monitor PPE donning/doffing

- Attention, "slow is smooth. smooth is fast"

- First put on your PPE before entering the room

- Engage the team, role designate, avoid contamination of Environment

PCS framework ${ }^{14}$ comprises 2 key sections: Screening and Actions. Patient undergoes Screening: for infectious symptoms, unclear history, lack of ability to communicate, or features suggestive of an alternate diagnosis. Any of these features trigger a PCS. As community transmission of COVID-19 became more prevalent, travel history became a less important parameter in the PCS protocol. The code then proceeds using appropriate actions. This includes: PPE for standard or aerosolizing procedures, masking of the patient, and considerations for avoidance of AGMPs, and early airway management. Emphasis is placed on Crisis Resource Management. We introduce the concept of SAFE code strokes: Safety leader for ensuring donning/doffing of PPE. Attention to not rushing, and having situational awareness. First putting on PPE for all team members. Engagement of the team and avoidance of Environmental contamination. Physician discretion is paramount when designating a code stroke a PCS. Local practices and regulations should be followed with regard to each of the Actions as part of a PCS. AGMPs = Aerosol Generating Medical Procedures; COVID-19 = coronavirus disease 2019; PCS = Protected code stroke; $\mathrm{PPE}=$ personal protective equipment. 


\section{Maintaining Neurology Education}

Similar to other institutions, our university and hospitals mandated the cancellation of in-person teaching rounds and conferences, including our weekly academic half-day. In response, we transitioned academic half-day to a videoconferencing platform, with recorded lectures posted to our online portal. To promote interactivity, all residents are encouraged to keep cameras on and use the chat function to ask questions during teaching. Furthermore, we have implemented Neurology Quality and Innovation Lab (NQIL) COVID rounds every 2-3 weeks, during which a resident presents a COVID-19-related case encountered on the neurology service and the group discusses educational, ethical, and safety concerns.

Small-group teaching at each hospital is conducted over the same virtual platform and shared with other academic sites, creating a city-wide videoconference-based teaching curriculum for residents and expanding access to learning opportunities for residents at all sites. This is particularly important for backup residents to maintain productivity, education, and a sense of belonging. Additional self-learning online resources, including modules from the American Academy of Neurology, are being curated and posted on our online portal. Our online portal is also being used to disseminate COVID-19 guidance and policies to centralize important communications and resources.

\section{The Trainee Perspective}

The effect of outbreaks on trainees and educational programs was described during the 2003 SARS outbreak and included fear of personal safety; a willingness to care for patients with SARS, but a pressure to be the primary frontline HCP; frustrations with obtaining consultations; the toll on personal well-being resulting from social isolation; and compromised learning experiences due to canceled core rotations and teaching. ${ }^{14}$ In addition, mixed messages and dynamic information early on in the SARS outbreak were a source of anxiety for medical residents as well, whereas regular updates from multiple sources did help relieve this anxiety. ${ }^{14}$

Uncertainty of the unfolding COVID-19 pandemic, rapidly changing policies, fears of becoming ill or transmitting illness to family and friends, and cancellation of outpatient neurology electives and redeployment have all contributed to heightened anxiety among our trainees. The rapid response to COVID-19 resulted in continuous hospital and departmental policy changes, which were sometimes conflicting. To effectively monitor the situation and plan accordingly, we implemented several strategies to collate diverse information from residents at each site (e.g., resident illness and shortages, workload, and changes in site-specific guidance). Online messaging groups were created with the chief residents acting as intermediaries between frontline residents and academic staff across sites. We initiated weekly virtual town hall meetings where rapidly changing policies from various stakeholders (Division of Neurology, Department of
Medicine, Postgraduate Medical Education, and individual hospitals) are discussed. The town hall, while maintaining a sense of community during physical distancing, also enables our program to monitor and receive real-time feedback on our training modifications and collaboratively discuss solutions.

Another qualitative study of staff physicians during the SARS outbreak identified several themes surrounding the erosion of medical professionalism in times of health care crisis, including the balance between personal safety and patient care needs and the physician-patient relationship. ${ }^{15}$ Our program's weekly town hall is a venue to discuss professionalism issues, including maintaining confidentiality of ill colleagues and balancing personal risk with patient care. We check in frequently to ensure that personal safety is being maintained and to monitor variations in local practices regarding the use and supply of PPE. During the pandemic, no hospital visitors have been allowed, and residents have found that they are taking on a greater role in supporting and comforting patients with substantial neurologic disability - similar to SARS $2003 .{ }^{16}$ In light of this, our weekly town halls enable residents to share their experiences with others and to provide their support for one another.

Our program's annual resident retreat is an opportunity to provide constructive feedback for the purpose of programmatic continuous quality improvement. This year we conducted a virtual retreat to ensure that residents were still provided this annual opportunity. A prominent concern raised by residents is the disruption to their training and learning. For our second-, fourth-, and fifth-year residents, COVID-19 struck at the beginning of an 8-week subspecialty clinic rotation designed to explore different areas of outpatient neurology—one of our program's highlights. Because of cancellation of most outpatient clinics, many residents expressed disappointment for missing this foundational learning experience and career exploration opportunity. The program is exploring ways to partially make up this learning experience.

The COVID-19 pandemic has rapidly altered the landscape of academic medicine, both in terms of provision of care and in our duties as educators and learners. In a short time, we adopted creative and flexible solutions to balance clinical care and education in the safest manner. Neurologists will undoubtedly care for patients with COVID-19, ${ }^{11}$ and it is therefore prudent that neurology residency programs have multiple levels of contingency plans in place for trainees during this global pandemic.

We have highlighted novel modifications to our training program, with practical examples for other training programs to consider. Specifically, the split-team model facilitates rapid adaptation to emerging service needs, resident illness, and quarantine while promoting resident safety through physical distancing. We have also highlighted changes to hospitalspecific and program-wide neurology education. Finally, we developed the PCS framework intended to safeguard neurologists and trainees during hyperacute stroke management of patients with suspected COVID-19. ${ }^{13}$ 
Neurology residency programs need to remain nimble, sensitive, and responsive to trainee needs as the pandemic evolves and continue to share knowledge with other programs and colleagues. Creating an ongoing mechanism to receive regular feedback from trainees on the frontlines through weekly town halls has enabled us to be up to date and responsive to evolving trainee needs during the COVID-19 pandemic.

\section{Study Funding}

No targeted funding reported.

\section{Disclosure}

R. Muir, P. Gros, R. Ure, and S. Mitchell do not have conflicts of interest or relevant disclosures to disclose. C. Kassardjian has participated in advisory board capacity for Alexion, Takeda, and Akcea. He has received honoraria from Alexion and Sanofi Genzyme. A. Izenberg has participated in advisory board capacity for Alexion, Takeda, Biogen, Roche, and Akcea. P. Tai, H. Khosravani, and D. Chan do not have conflicts of interest or relevant disclosures to disclose. Full disclosure form information provided by the authors is available with the full text of this article at Neurology.org/cp.

\section{Publication History}

Received by Neurology: Clinical Practice April 16, 2020. Accepted in final form June 12, 2020.

\section{Appendix Authors}

\begin{tabular}{|c|c|c|}
\hline Name & Location & Contribution \\
\hline Ryan T. Muir, MD & $\begin{array}{l}\text { Adult Neurology } \\
\text { Residency Training } \\
\text { Program, University of } \\
\text { Toronto }\end{array}$ & $\begin{array}{l}\text { Study conception and } \\
\text { design, drafted the } \\
\text { manuscript for } \\
\text { intellectual content, and } \\
\text { revised the manuscript } \\
\text { for intellectual } \\
\text { contribution }\end{array}$ \\
\hline Priti Gros, MD & $\begin{array}{l}\text { Adult Neurology } \\
\text { Residency Training } \\
\text { Program, University of } \\
\text { Toronto }\end{array}$ & $\begin{array}{l}\text { Created table 1, drafted } \\
\text { the manuscript for } \\
\text { intellectual content, and } \\
\text { revised the manuscript } \\
\text { for intellectual } \\
\text { contribution }\end{array}$ \\
\hline Robert Ure, MD & $\begin{array}{l}\text { Adult Neurology } \\
\text { Residency Training } \\
\text { Program, University of } \\
\text { Toronto }\end{array}$ & $\begin{array}{l}\text { Created table 1, drafted } \\
\text { the manuscript for } \\
\text { intellectual content, and } \\
\text { revised the manuscript for } \\
\text { intellectual contribution }\end{array}$ \\
\hline $\begin{array}{l}\text { Sara B. Mitchell, } \\
\text { MD, MPH }\end{array}$ & $\begin{array}{l}\text { Division of Neurology, } \\
\text { Department of Medicine, } \\
\text { Department of Psychiatry } \\
\text { Sunnybrook Health } \\
\text { Sciences Centre, } \\
\text { University of Toronto }\end{array}$ & $\begin{array}{l}\text { Drafted the manuscript } \\
\text { for intellectual content } \\
\text { and revised the } \\
\text { manuscript for } \\
\text { intellectual contribution }\end{array}$ \\
\hline $\begin{array}{l}\text { Charles D. } \\
\text { Kassardjian, MD, } \\
\text { MSc }\end{array}$ & $\begin{array}{l}\text { Division of Neurology, } \\
\text { Department of Medicine, } \\
\text { St. Michael's Hospital, } \\
\text { University of Toronto }\end{array}$ & $\begin{array}{l}\text { Drafted the manuscript } \\
\text { for intellectual content } \\
\text { and revised the } \\
\text { manuscript for } \\
\text { intellectual contribution }\end{array}$ \\
\hline
\end{tabular}

Appendix (continued)

\begin{tabular}{|c|c|c|}
\hline Name & Location & Contribution \\
\hline $\begin{array}{l}\text { Aaron Izenberg, } \\
\text { MD, MSc }\end{array}$ & $\begin{array}{l}\text { Division of Neurology, } \\
\text { Department of Medicine, } \\
\text { Sunnybrook Health } \\
\text { Sciences Centre, } \\
\text { University of Toronto }\end{array}$ & $\begin{array}{l}\text { Study conception and } \\
\text { design, drafted the } \\
\text { manuscript for } \\
\text { intellectual content, and } \\
\text { revised the manuscript } \\
\text { for intellectual } \\
\text { contribution }\end{array}$ \\
\hline Peter Tai, MD & $\begin{array}{l}\text { Division of Neurology, } \\
\text { Department of Medicine, } \\
\text { University Health } \\
\text { Network, University of } \\
\text { Toronto }\end{array}$ & $\begin{array}{l}\text { Study conception and } \\
\text { design, drafted the } \\
\text { manuscript for } \\
\text { intellectual content, and } \\
\text { revised the manuscript } \\
\text { for intellectual } \\
\text { contribution }\end{array}$ \\
\hline $\begin{array}{l}\text { Houman } \\
\text { Khosravani, MD, } \\
\text { PhD }\end{array}$ & $\begin{array}{l}\text { Division of Neurology, } \\
\text { Department of Medicine, } \\
\text { Sunnybrook Health } \\
\text { Sciences Centre, } \\
\text { University of Toronto }\end{array}$ & $\begin{array}{l}\text { Study conception and } \\
\text { design, created figure 1, } \\
\text { drafted the manuscript } \\
\text { for intellectual content, } \\
\text { and revised the } \\
\text { manuscript for } \\
\text { intellectual contribution }\end{array}$ \\
\hline $\begin{array}{l}\text { David K. Chan, } \\
\text { MD, MEd }\end{array}$ & $\begin{array}{l}\text { Division of Neurology, } \\
\text { Department of Medicine, } \\
\text { St. Michael's Hospital, } \\
\text { University of Toronto }\end{array}$ & $\begin{array}{l}\text { Study conception and } \\
\text { design, drafted the } \\
\text { manuscript for } \\
\text { intellectual content, and } \\
\text { revised the manuscript } \\
\text { for intellectual } \\
\text { contribution }\end{array}$ \\
\hline
\end{tabular}

\section{References}

1. Li Q, Guan X, Wu P, et al. Early transmission dynamics in Wuhan, China, of novel coronavirus-infected pneumonia. N Engl J Med 2020;382:1199-1207.

2. Dong E, Du H, Gardner L. An interactive web-based dashboard to track COVID-19 in real time. Lancet Infect Dis 2020;3099:19-20.

3. Guan WJ, Ni ZY, Hu Y, et al. Clinical characteristics of coronavirus disease 2019 in China. N Engl J Med 2020;382:1708-1720.

4. Mao L, Jin H, Wang M, et al. Neurologic manifestations of hospitalized patients with coronavirus disease 2019 in Wuhan, China. JAMA Neurol 2020;77:1-9.

5. Poyiadji N, Shahin G, Noujaim D, Stone M, Patel S, Griffith B. COVID-19associated acute hemorrhagic necrotizing encephalopathy: CT and MRI features. Radiology Epub 2020 Mar 31.

6. Oxley TJ, Mocco J, Majidi S, et al. Large-vessel stroke as a presenting feature of Covid19 in the young. N Engl J Med 2020;382:e60.

7. Gutiérrez-Ortiz C, Méndez A, Rodrigo-Rey S, et al. Miller Fisher Syndrome and polyneuritis cranialis in COVID-19. Neurology Epub 2020 Apr 17.

8. Sedaghat Z, Karimi N. Guillain Barre syndrome associated with COVID-19 infection: a case report. J Clin Neurosci 2020;76:233-235.

9. Brownlee W, Bourdette D, Broadley S, Killestein J, Ciccarelli O. Treating multiple sclerosis and neuromyelitis optica spectrum disorder during the COVID-19 pandemic. Neurology 2020;94:949-952.

10. Guidon AC, Amato AA. COVID-19 and neuromuscular disorders. Neurology 2020; 94:959-969.

11. Nath A. Neurologic complications of coronavirus infections. Neurology 2020;94: 809-810.

12. De Wit E, Van Doremalen N, Falzarano D, Munster VJ. SARS and MERS: recent insights into emerging coronaviruses. Nat Rev Microbiol 2016;14: 523-534.

13. Khosravani H, Rajendram P, Notario L, Chapman MG, Menon BK. Protected code stroke: hyperacute stroke management during the COVID-19 pandemic. Stroke 2020;51:1891-1895.

14. Rambaldini G, Wilson K, Rath D, et al. The impact of severe acute respiratory syndrome on medical house staff: a qualitative study. J Gen Intern Med 2005;20: 381-385.

15. Straus SE, Wilson K, Rambaldini G, et al. Severe acute respiratory syndrome and its impact on professionalism: qualitative study of physicians' behaviour during an emerging healthcare crisis. Br Med J 2004;329:83-85.

16. Styra R, Hawryluck L, Robinson S, Kasapinovic S, Fones C, Gold WL. Impact on health care workers employed in high-risk areas during the Toronto SARS outbreak. J Psychosom Res 2008;64:177-183. 


\title{
Neurology ${ }^{\circ}$ Clinical Practice
}

\author{
Modification to Neurology Residency Training: The Toronto Neurology COVID-19 \\ Pandemic Experience \\ Ryan T. Muir, Priti Gros, Robert Ure, et al.
}

Neurol Clin Pract 2021;11; e165-e169 Published Online before print June 22, 2020

DOI 10.1212/CPJ.0000000000000894

This information is current as of June 22, 2020

\begin{abstract}
Updated Information \&
Services

including high resolution figures, can be found at:

http://cp.neurology.org/content/11/2/e165.full.html

References

This article cites 14 articles, 4 of which you can access for free at: http://cp.neurology.org/content/11/2/e165.full.html\#\#ref-list-1

Citations

This article has been cited by 1 HighWire-hosted articles:

http://cp.neurology.org/content/11/2/e165.full.html\#\#otherarticles

Subspecialty Collections

This article, along with others on similar topics, appears in the following collection(s):

All Cerebrovascular disease/Stroke

http://cp.neurology.org//cgi/collection/all_cerebrovascular_disease_str oke

COVID-19

http://cp.neurology.org//cgi/collection/covid_19

Models of care

http://cp.neurology.org//cgi/collection/models_of_care

Training-international

http://cp.neurology.org//cgi/collection/training_international

Permissions \& Licensing

Information about reproducing this article in parts (figures,tables) or in its entirety can be found online at:

http://cp.neurology.org/misc/about.xhtml\#permissions

Reprints

Information about ordering reprints can be found online:

http://cp.neurology.org/misc/addir.xhtml\#reprintsus
\end{abstract}

Neurol Clin Pract is an official journal of the American Academy of Neurology. Published continuously since 2011, it is now a bimonthly with 6 issues per year. Copyright ( 2020 American Academy of Neurology. All rights reserved. Print ISSN: 2163-0402. Online ISSN: 2163-0933.

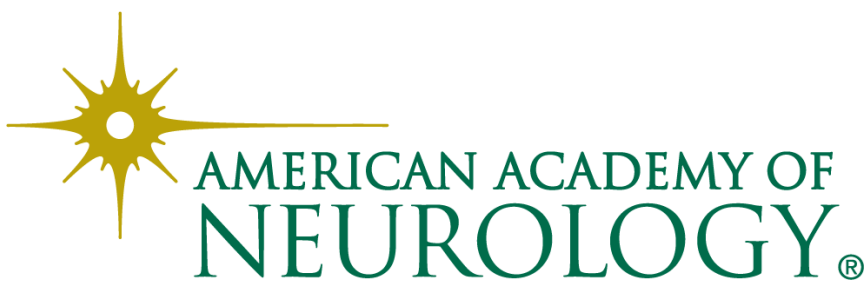

